\title{
Contrasts and similarities in economic performance of migrant entrepreneurs
}

\author{
Mediha Sahin ${ }^{1}$, Peter Nijkamp ${ }^{1,2^{*}}$ and Soushi Suzuki ${ }^{3}$
}

\author{
* Correspondence: p.nijkamp@vu.nl \\ ${ }^{1}$ Department of Spatial Economics, \\ VU University, De Boelelaan 1105, \\ 1081 HV Amsterdam, The \\ Netherlands \\ ${ }^{2}$ A. Mickiewicz University, Poznan, \\ Poland \\ Full list of author information is \\ available at the end of the article
}

\begin{abstract}
In recent years, migrant entrepreneurs have come to occupy a prominent place in the SME sector in many cities in developed countries, with varying degrees of success. The concept of migrant entrepreneurship suggests a homogeneous set of actors, but it remains to be seen whether differences in cultural and ethnic backgrounds, in education, in age and gender, and in motivational profiles lead to contrasting business outcomes. The present paper aims to identify and compare differences in the economic performance of individual migrant business firms on the basis of a quantitative assessment of the drivers of their efficiency profiles. In this context, we will address in particular the drivers and barriers for the heterogeneous business strategies of specific classes of migrant entrepreneurs. After the use of a multivariate statistical analysis, a modern operational approach-originating from organizational theory-that aims to make a comparative study of quantitative efficiency differences between individual decision-making units (DMUs), viz. Data Envelopment Analysis (DEA) is employed. DEA is used here to assess relative performance differences between distinct categories of migrant entrepreneurs in the city of Amsterdam. A wealth of relevant data has been collected by systematic, personally-supervised interviews and questionnaires, and these contain a variety of efficiency-oriented indicators, on both the input and the output side. Several additional analyses - using multivariate cross-analysis methods - are also carried out to test the robustness of our findings by, inter alia, investigating the influence of specific socio-cultural ethnic groups, levels of education, first-and second-generation migrants, and age. Finally, the paper offers some lessons on entrepreneurship strategies. Jel codes: R10, O15, L26.

Keywords: Data envelopment analysis; Migrant entrepreneurship; Efficiency performance
\end{abstract}

\section{Migrants in urban business}

\subsection{Introduction}

Recent years have shown a growing interest in innovative and entrepreneurial behaviour as an engine for economic growth. The economic performance of business agents can be measured by indicators such as innovativeness, birth/death rates, or investments, while there are many underlying key factors, such as quality of labour, education, geographic accessibility, network usage, or urban orientation. This means that business firms in an urban economic system may essentially be conceived of as decision-making units (DMUs) of a multi-product nature, whose task it is to maximize their efficiency in a competitive urban environment.

\section{글}

(C) 2014 Sahin et al.; licensee Springer. This is an open access article distributed under the terms of the Creative Commons Attribution License (http://creativecommons.org/licenses/by/2.0), which permits unrestricted use, distribution, and reproduction in any medium, provided the original work is properly cited. 
Urban areas are becoming platforms of competition, especially for SMEs (Sassen 1991). Through their agglomeration advantages, cities offer the most competitive spatial constellations, and are thus a source of permanent vitality, despite the diseconomies of scale present in many cities (Glaeser et al. 2000). The success of cities usually depends on two essential assets, viz. knowledge and entrepreneurship (see, e.g., Acs et al. 2002; Glaeser 2011). The first asset, knowledge - in combination with scientific research and education -, is one of the driving forces for urban competitiveness and growth. The second factor, i.e. entrepreneurship, is equally important, as entrepreneurship forms the engine for innovation, and hence for the drastic economic and technological transformations that are necessary for vital and growing cities (see Audretsch et al. 2007; van Geenhuizen and Nijkamp 2012; Nijkamp 2003; Santarelli 2006).

Most large cities, in a globalized world, are increasingly the home of international migrants and centres of accelerated growth, in which SMEs and innovative entrepreneurship play a key role in inducing urban economic development. These cities house many migrant entrepreneurs who exert a big, but often unknown, influence on the urban economy. Migrants make up a significant part of urban dwellers, and their business is critical for a sustainable development of cities, especially because of their large share in SMEs.

\subsection{Migrant entrepreneurship}

According to Choenni (1997), migrant entrepreneurship refers to business activities undertaken by migrants with a specific socio-cultural and ethnic background or migrant origin, and it distinguishes itself from 'normal' entrepreneurship through its orientation on migrant products, on migrant market customers, or on indigenous migrant business strategies(see also Sahin et al. 2009, 2010). Migrant entrepreneurship generates many urban-economic returns through the use of suitable market niches, and helps to reinforce the SME sector as a complement to bigger mainstream companies. In addition, existing business can also benefit from the experience and knowledge of migrant businesses that emerge as a consequence of the rise of migrant communities, with their protected markets and networks of mutual support. As the migrant share grows and diversifies, the opportunities for related migrant suppliers and customers will also rise (Cormack and Niessen 2002). Nowadays, migrant entrepreneurship is often seen as a great chance for revitalizing urban economic life. The seminal work of Waldinger has been particularly instrumental in this context (see, e.g., Waldinger 1988, 1996; Waldinger et al. 1990). In his view, migrant businesses find their origin in the interplay of opportunity structures, group characteristics, and strategies for adapting to the urban environment.

There has been an extensive discussion in the literature on the varying economic impact of migrants, especially at local and regional levels (see, e.g., Borjas 1991; de Graaff and de Groot 2004; Greenwood 1994; Longhi et al. 2007; Nijkamp et al. 2012). Despite the fact that foreign migrants do not, in general, have a demonstrable negative impact on the socio-economic conditions of native people, there is still much concern worldwide on the possible negative consequences of the international migration wave. Against this background, the phenomenon of migrant entrepreneurship has gained much popularity, as this type of self-employment has given a strong impetus to urban revitalization, while avoiding the negative impacts on the labour market that are often 
perceived (see, e.g., Bates 1997; Baycan-Levent et al. 2009; Cummings 1980, or Razin and Light 1988). Migrant entrepreneurship is also frequently regarded as an important self-organizing activity through which migrant groups are able to improve their feeble socio-economic position (Baycan-Levent et al. 2003). Migrant entrepreneurship is thus frequently seen as a sign of hope for urban economies in decay.

\subsection{Backgrounds of migrant entrepreneurship}

In general, migrants seem to be more inclined towards risk-taking in self-employment than natives or those people who remain in the home country. They usually migrate with a strong desire for social advancement, and are thus more likely to take business risks and become self-employed. The difficulty of getting work has encouraged several migrants to set up their own business, especially in larger cities. Migrant minorities usually appear to be a highly motivated and qualified entrepreneurial group. Ethnic or migrant entrepreneurship in cities provides the opportunities for, and access to, economic growth, equal opportunities, and upward mobility for many of those who have traditionally been excluded from business, including migrant minorities (see Sahin 2012, for a broad overview).

There are several other reasons why migrants prefer entrepreneurship: to be independent or to be their own boss; earn extra income; gain some work experience; maintain family tradition; dissatisfaction with the previous job; need for flexibility; desire to make a career of to have a job in business; ideological reasons, or leadership qualities (Baycan-Levent et al. 2003, Metcalf et al. 1996; Clark and Drinkwater 1998). In an early study, Jenkins (1984) has identified three basic explanatory models of ethnic involvement in business, viz. (i) the economic opportunity model; (ii) the culture model; and (iii) the reaction model. The economic opportunity model regards migrant minority businesses as relying on the market for their fortunes. The culture model assumes that some cultures predispose group members towards the successful pursuit of entrepreneurial goals. The reaction model assumes that self-employment amongst members of migrant minority groups is a reaction against racism and blocked avenues of social mobility, a means of surviving in the margins of a white-dominated society (see also Sahin 2012).

The scientific literature on ethnic (migrant, minority, coloured) entrepreneurship is vast. Starting in the USA, in the past few decades research on this issue has boomed. Migrant entrepreneurship studies focussed sometimes on specific ethnic groups (e.g., Chinese, Indians), sometimes on social bonds between migrant communities, sometimes on ethnic product markets, sometimes on urban-economic melting pot phenomena, and sometimes on migrant business strategies. In recent years, a real avalanche of literature has been published on migrant entrepreneurship, too much to be covered and reviewed in this present article. For some recent overviews, we refer to Kloosterman and Rath (2001), Oliveira and Rath (2008), Baycan-Levent et al. (2004), Dana (2006), Sahin et al. (2009) and Sahin (2012).

It should be noted that migrant entrepreneurship is clearly not a uniform phenomenon, as migrants may have totally different cultures, languages, habits, motives and ambitions. An underresearched issue in the migrant entrepreneurship literature is the disparity in economic performance among different groups of migrant entrepreneurs. Our study aims to fill this gap and to identify the extent and backgrounds of these differences in business performance. We will introduce this topic by providing a concise literature overview. 
Kloosterman and Rath (2001) state that the distinctive traits of ethnic entrepreneurship when compared with traditional entrepreneurship are: the origins of the entrepreneurs; the management strategies; the products and services; and the personnel and customers, which in most cases are both of ethnic origin. Therefore, ethnic entrepreneurs often have no contact outside their own immigrant group; this is mainly caused by their lack of knowledge of the host country language and also of the preferences and needs of the locals (Rusinovic 2008). Therefore, the main issue related to ethnic entrepreneurship is the predominance of informal networks or mixed embeddedness, as Kloosterman et al. (1999) propose to call it, which, in many cases, they consider to have a positive effect on the survival rate of ethnic firms.

With the ongoing rise in urban migrants, the economic power of these groups has become a recognised fact that no urban policy can afford to ignore. According to Kloosterman and Rath (2001) ethnic entrepreneurs 'can stretch or even challenge the conventional meaning of entrepreneurship'. It is also noteworthy that young people of ethnic origin - often belonging to the second generation - are progressing more than ever before in education and the workforce (Cormack and Niessen 2002). Therefore, although previously considered to lack financial and educational resources, nowadays many immigrants from less-developed countries present a different profile, being often highly-educated and skilled (Kloosterman and Rath 2001), and consequently more interested in offering innovative products.

Chaganti and Greene (2000) showed several significant differences between natives and migrants on variables relating to the entrepreneurs' background characteristics, business-related goals, cultural values, business strategies, and business performance. A prominent characteristic of migrant entrepreneurship is the influence of family and coethnic labour on the business. Co-ethnic labour is an important source of competitive advantage for migrant business, since it is cheap and the problem of supervision is made easier (Mitter 1986). Surveys conducted in different European countries show that most migrant businesses have been established with the financial and human capital support of their families. Migrant entrepreneurs regularly do not have sufficient formal security to be able to obtain loans through banks, so they often resort to their own families or friends to finance their enterprises. They also often apply for relatively small loans, which are less interesting for banks, since the same largely similar fixed costs are attached to the provision of a small loan as to larger loans. In addition, many migrants do not seem to know how to approach financial institutions, and are not always familiar with the conditions for loan applications.

A consistent finding from previous research on traditional migrant minority businesses is their low inclination or willingness to use mainstream business support associations or agencies, often relying instead on self-help and informal sources of assistance (see Deakins et al. 1997; Ram and Jones-Evans 1998; Ram and Smallbone 2002; Carter and Jones-Evans 2006). The low interest of migrant entrepreneurs to use mainstream business support and public agencies is caused by demand- and supply-side circumstances. Demand-side issues are related to a low level of perceived need of (or a lack of interest in) receiving external assistance. Supply-side issues concern the inability to liaise with other firms, to inadequate information systems, and to the unsatisfactory scope of product-oriented approaches used by many support agencies. However, it was recently shown that second-generation entrepreneurs of different ethnic origins have less difficulty in approaching banks (Rusinovic 
2006), and make less use of financial capital from their own group, because they have the abilities and skills to make use of official institutions for vocational guidance. Migrant entrepreneurs usually participate less in formal networks of native firms, such as retailer groups, trade associations, and franchise organizations.

\subsection{Aims and scope}

Not all individual entrepreneurs are equally successful in achieving their business goals and, therefore, due insight into the diverse reasons for these individual differences is needed. The focus of the present study is, in particular, on differences in business achievement indicators among various groups of ethnic (migrant) enterprises in an urban system. This focus is warranted, as migrant entrepreneurs - mainly SMEs - are predominantly found in large cities. The present study aims to identify contrasts in business performance of urban migrant entrepreneurs, from the viewpoint of ethnic, cultural, socio-economic and socio-psychological determinants. Our research addresses the relative efficiency of individual migrant entrepreneurs of distinct ethnic origins in a given urban economy, notably the city of Amsterdam. We employ an analytical tool from the organizational sciences, namely Data Envelopment Analysis (DEA), in order to compare the economic performance of distinct migrant entrepreneurs. Methodologically, we also present a new efficiency-improving projection model for a decisionmaking unit (DMU), so as to obtain a more appropriate movement towards the efficiency frontier of the production system of migrant entrepreneurs (see Section 4). Our efficiency analysis is based on a standard assumption in DEA that the DMU is essentially a multi-product firm with multiple production inputs (e.g., labour, socio-cultural network access) and multiple production outputs (e.g., profits, market share, socioeconomic recognition, etc.), whose smart combination will ultimately be decisive for innovative business performance in a competitive urban environment.

The main proposition put forward in the present study is that migrant entrepreneurship is a very diversified phenomenon with distinct differences in business performance, depending on ethnic background, education, social networks, and the like. We therefore, aim to test the hypothesis that there are several important drivers (inputs) that may be different for distinct migrant entrepreneurs groups, and that may cause significant variations in the business performance of these firms (outputs).

Our study will investigate the entrepreneurial performance of migrants - with a focus on personal characteristics, socio-cultural bonds, and managerial skills - from a multicultural urban perspective in order to perform a quantitative assessment of critical success factors (CSFs), with the aim of assessing or improving their relative business performance. Due empirical insight into entrepreneurial motives and the achievements of migrants is also desirable for enhancing the socio-economic vitality of the city, in particular for developing a promising policy strategy in the modern urban melting pot of varied cultures. Our approach will be applied to an extensive data set on the motives, CSFs, and cultural backgrounds of a sample of migrant entrepreneurs in Amsterdam. The data have been collected from recent survey questionnaires distributed among three dominant groups of migrant entrepreneurs in this city, viz. Moroccans, Surinamese, and Turks. The remaining part of the paper is organized as follows. First, we briefly describe some of the main features of migrant entrepreneurs in the Netherlands, and in Amsterdam in particular. Then, we describe the fieldwork and our database 
(Section 3). A subsequent section outlines the essence of, and justification for, the use of the DEA model employed in our empirical application, while next in Section 5 a presentation and interpretation of the various results obtained will be offered. Finally, the last section provides some concluding lessons.

\section{Migrants as entrepreneurial heroes in the Netherlands}

The Netherlands has become a typical immigration country over past decades. Currently, the Netherlands has a total migrant population of more than $2 \mathrm{mln}$, of which more than half is represented by the first-generation immigrants. Furthermore, approx. 40 per cent of the total migrant population lives in the four biggest cities of the Netherlands (Rotterdam, Amsterdam, The Hague and Utrecht) (Tillie and Slijper 2006). The larger migrant groups are of Turkish, Moroccan, and Surinamese origin, followed by migrants from the Dutch Antilles.

The last three decades have been marked by a permanent increase in the number of migrant entrepreneurs in the Netherlands. Their growth rates were higher than those of native entrepreneurs in the Netherlands. The identification of a migrant entrepreneur is fraught with many problems, so that at best a reasonable guess can be made. More details on the estimated number of migrant entrepreneurs can be found in EIM (2004), Rusinovic (2008) and Sahin (2012). Nowadays, the major cities in the Netherlands have a rich variety of migrant entrepreneurs. The biggest share of these migrant enterprises and entrepreneurs can be found in the four Dutch big cities; they resemble sometimes a 'Soho' economy. Furthermore, entrepreneurship among migrants is not only concentrated geographically, but is also concentrated in specific sectors, such as hospitality, retailing, and repair services. Many migrants in the Netherlands originate from non-Western countries: Turkey, Morocco, Surinam, and the Dutch Antilles. Migrant entrepreneurs do not form homogeneous groups, but are composed of people with rather different socio-economic and cultural backgrounds. As a consequence, the success in establishing their own enterprise and their business performance/efficiency is most likely different among various minority groups. Also, the entrepreneurship rates of the Turkish and Moroccan entrepreneurs are quite different. The explanation for such differences may be related to the cultural background of the migrants. Whereas many first-generation migrants from Turkey already had an entrepreneurial background in their country of birth, migrants from Morocco showed considerably lower entrepreneurial rates. Therefore, the later Turkish generations already come from families with an entrepreneurial background, which may also cause the differences in motivation and orientation (see also Sahin 2012).

Migrant minorities consist of two types of migrants. One is the first-generation group, consisting of traditional migrants who were directly recruited for employment reasons. This group is in general less educated, with most of their education having been acquired in their country of origin. The other group is the second generation, consisting of young dependants born in the host countries where they have had their entire education. This group masters the language of the host country better than the first generation, and is relatively more qualified and acquainted with the local labour market. Not surprisingly, this group is generally found to be more ambitious and selective in choosing a job. Frequently, first-generation migrant entrepreneurs undertake their own business impulsively, without first making a detailed study of the market 
prospects. As a consequence of this start, they serve the same customer group with the same products and services as their competitors without any distinction. This may lead to enormous price competition, a falling behind in entrepreneurs income, and hence a high fall-out rate amongst young migrant businesses. Sahin (2012) offers a broad perspective on these issues.

Migrant entrepreneurs in the Netherlands come from all over the world and are clearly not a uniform business group, but have different ethnic origins, network relationships, cultural adjustment patterns, business styles, and so forth. Consequently, it may be interesting to test whether distinct migrant groups have significant differences in their economic performance and why. As can be seen from the illustrative Table 1, the rates of self-employment are quite divergent among different groups. Generally, there is also a difference in the sectoral choice of first- and second-generation migrants. The former choose to become self-employed more often in the traditional sectors, i.e. retail, hotels, and catering. On the other hand, the latter are predominantly active in the business and producer services sector. Therefore, most likely the sectoral choice of secondgeneration entrepreneurs tends to resemble that of the natives more than that of their forerunners. The three classes of migrants, i.e., Turks, Moroccans, and Surinamese/Dutch Antilleans, account for the largest share of foreign migrants in the Netherlands. Their shares are largely comparable, in relation to other migrant groups which are much smaller in size.

There are obviously significant differences in business performance of these firms. Figure 1 shows the differences in the profits of first- and second-generation migrant entrepreneurs from the four main groups in the Netherlands. T1 and T2 refer, respectively, to first- and second-generation Turkish entrepreneurs; M1 and M2 refer, respectively, to first- and second-generation Moroccan entrepreneurs; S1 and S2 refer, respectively, to first- and second-generation Surinamese entrepreneurs; and A1 and A2 refer to first- and second-generation Antillean entrepreneurs. Figure 1 indicates that the Antilleans and Surinamese seem very successful; the second-generation entrepreneurs in these groups have almost the same profits as those of the first generation. But, when we look at the migrants from Turkey and Morocco, the profits of the firstgeneration entrepreneurs are higher than that of the second generation. Although the Surinamese and Antillean groups are much smaller than the other two groups, they have higher profits. This intriguing finding may be caused by differences in their entrepreneurial behaviour (see for details Sahin 2012). Thus, it is important to trace the reasons for such differences, and this is our research goal. In our empirical research, we use a modern research tool for assessing individual performance differences among DMUs, based on DEA. In the next section, we will first introduce our empirical research approach.

Table 1 Number of entrepreneurs (x1,000), 1999-2004

\begin{tabular}{lllll}
\hline Year & Turks & Moroccans & Netherlands Antilles & Surinamese \\
\hline 1999 & 7.9 & 2.8 & 1.5 & 6.4 \\
2000 & 9.2 & 3.3 & 1.8 & 7.1 \\
2001 & 11.0 & 4.0 & 2.0 & 7.8 \\
2002 & 11.5 & 4.3 & 2.1 & 7.9 \\
2003 & 11.9 & 4.4 & 2.2 & 8.0 \\
2004 & 11.8 & 4.6 & 2.1 & 7.7 \\
\hline
\end{tabular}

Source: CBS 2007. 


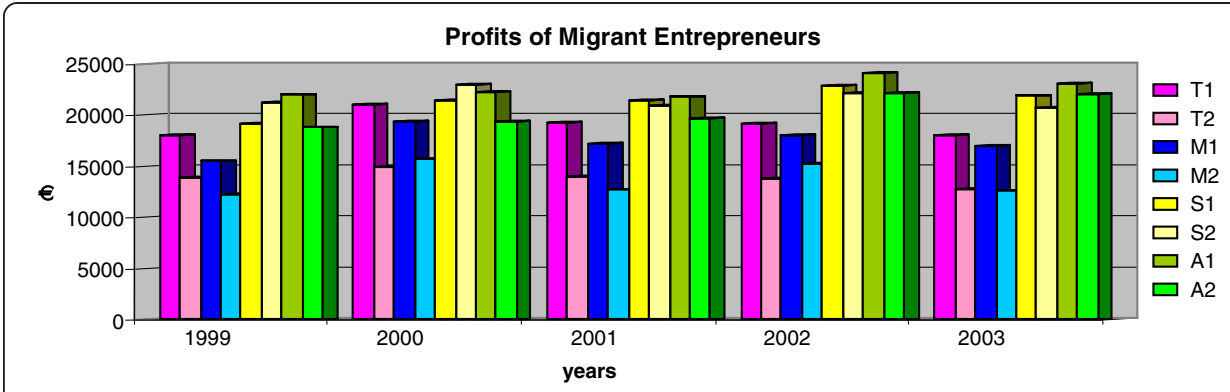

Figure 1 Distribution of profits among first-and second-generation migrant entrepreneurs. Source: CBS, 2007.

\section{Research design and database}

\subsection{Research approach}

As mentioned before, our aim is to undertake an efficiency analysis - based on DEA principles - among individual migrant entrepreneurs of three main ethnic groups in the city of Amsterdam. The migrant entrepreneurship segment is gaining considerable importance in the business system of this city, but also has several weaknesses with various degrees of economic success. Hence, we are interested in the background factors that act as explanatory input variables for the economic performance indicators (outputs) in the migrant entrepreneurship business system in Amsterdam. Our study analyses the relative efficiency profile - in terms of market shares, growth in turnover, and profits - of both first- and second-generation migrant entrepreneurs, in the agegroup of approximately 18 to 65 years old. Our database stems from detailed and systematic interviews collected from 83 migrant entrepreneurs, mainly in the service sector, in Amsterdam. Data on migrant entrepreneurship in Dutch cites are scarce. An overview of available data source and entrepreneurial indicators can be found in Nijkamp and Sahin (2009). Clearly, for statistical purposes the ample size is not exceedingly high, but in a deterministic case study context in which DEA will be applied this is a relatively high number. This turned out to be a time-consuming and painstaking process, as migrant entrepreneurs are not very willing to talk openly about their business with unknown people. The selection process was based on the 'snow-ball' or 'networking' procedure; start with a first group of randomly found migrant entrepreneurs, and try to find more entrepreneurs who are willing to participate in an in-depth interview, sometimes supported by a systematic questionnaire. But the interviews appeared to reflect a reasonably converging perspective on motives and performances of distinct migrant groups. The population was confined to three migrant groups of people who are originally from Turkey, Morocco, and Surinam, because of their size and numbers in the service sector in the city. The approach was based on personallysupervised assistance in handling the various questions and, hence, once an entrepreneur had agreed to participate in this exercise, he was normally willing to complete the questionnaire. This type of approach - detailed micro-based case-study research - is rather usual in benchmarking studies in business administration and organisational sociology. The interviews and questionnaires contained several questions intended to gain information about the personal details of the entrepreneurs, their motivational factors, socio-cultural network participation, financial and market-related questions, 
and a set of assessment questions. From the range of questions in the survey, we have chosen those that could serve as indicators for the input factors of the production system of each migrant entrepreneur (DMU), and questions that would help assess the performance of the firms. The list of selected input and output indicators is presented in Table 2. Clearly, the ratio of output and input indicators is a productivity indicator; this will be further used in our DEA model (Section 4).

It should be noted that - for privacy reasons - there is no public database on migrant entrepreneurship in the Netherlands. All information has to be collected through carefully designed interview schemes. This is a rather painstaking process, regarding not only the interview itself, but also the preparation time required to identify an entrepreneur who is willing to participate. This leads necessarily to small samples (in our case, 83). However, for a benchmark analysis this is a reasonable number. An important test criterion for the size of the sample is whether the marginal information gain from the last interviewees is declining to zero (the 'zero marginal information gain stopping rule'). Statistical representativeness is then becoming less problematic in this type of field research (see for a justification and details, Yin 1984).

The analytical model used here is conceptually based on a micro-oriented total productivity approach (see Sahin 2012) Based on a comprehensive literature search on drivers of entrepreneurial performance, five major classes of input factors could be identified, namely: personal characteristics; size of enterprise; internal success factors; external success factors; and leadership factors. These five classes could next be subdivided into sets of measurable variables. These same was done for the output (performance) variables, namely: market share, growth in turnover, and profit. These sets of

Table 2 Input and output indicators of migrant entrepreneurs in a total productivity context

\begin{tabular}{|c|c|c|c|c|c|c|c|}
\hline \multicolumn{8}{|l|}{ INDICATORS } \\
\hline \multicolumn{5}{|l|}{ Input } & \multicolumn{3}{|l|}{ Output } \\
\hline$P C^{*}$ & $\mathrm{SE}^{*}$ & IS* & $\mathrm{ES}^{*}$ & $\mathrm{LS}^{*}$ & $\mathrm{MS}^{*}$ & $\mathrm{GT}^{*}$ & $\mathrm{PT}^{*}$ \\
\hline \multirow[t]{2}{*}{$\begin{array}{l}\text { Need for } \\
\text { achievement }\end{array}$} & \multirow{2}{*}{$\begin{array}{l}\text { Number of } \\
\text { full-time } \\
\text { employees }\end{array}$} & Commitment & \multirow{2}{*}{$\begin{array}{l}\text { Applicable } \\
\text { products and } \\
\text { services }\end{array}$} & $\begin{array}{l}\text { Negotiation } \\
\text { skills }\end{array}$ & \multirow[t]{8}{*}{$\begin{array}{l}\text { MARKET } \\
\text { SHARE }\end{array}$} & \multirow[t]{8}{*}{$\begin{array}{l}\text { GROWTH IN } \\
\text { TURN OVER }\end{array}$} & \multirow[t]{8}{*}{ PROFIT } \\
\hline & & $\begin{array}{l}\text { Culture of } \\
\text { enterprise }\end{array}$ & & $\begin{array}{l}\text { Communication } \\
\text { skills }\end{array}$ & & & \\
\hline \multirow{5}{*}{$\begin{array}{l}\text { Locus of } \\
\text { Control }\end{array}$} & \multirow{5}{*}{$\begin{array}{l}\text { Number of } \\
\text { part-time } \\
\text { employees }\end{array}$} & Administration & \multirow{2}{*}{$\begin{array}{l}\text { Availability } \\
\text { of finance }\end{array}$} & \multirow[t]{2}{*}{ Managerial skills } & & & \\
\hline & & Reliability & & & & & \\
\hline & & $\begin{array}{l}\text { Market } \\
\text { knowledge }\end{array}$ & \multirow[t]{2}{*}{$\begin{array}{l}\text { Expectations } \\
\text { of market }\end{array}$} & \multirow[t]{2}{*}{$\begin{array}{l}\text { Customer } \\
\text { relationships }\end{array}$} & & & \\
\hline & & $\begin{array}{l}\text { Customer } \\
\text { service }\end{array}$ & & & & & \\
\hline & & Personnel & Innovation & $\begin{array}{l}\text { Financial } \\
\text { knowledge }\end{array}$ & & & \\
\hline $\begin{array}{l}\text { Risk-taking } \\
\text { propensity }\end{array}$ & & Quality & & $\begin{array}{l}\text { Market } \\
\text { orientation }\end{array}$ & & & \\
\hline $\begin{array}{l}\text { Input factors: } \\
{ }^{*} P C \text { Personal ch } \\
\text { *SE Size of ente } \\
\text { *IS Internal succ } \\
{ }^{*} \text { ES External su } \\
\text { *LS Leadership. } \\
\text { Output factors: } \\
{ }^{*} \text { MS Market sha } \\
{ }^{*} G T \text { Growth in }\end{array}$ & $\begin{array}{l}\text { aracteristics ( } \mathrm{n} \\
\text { rprise. } \\
\text { ess. } \\
\text { cess. } \\
\end{array}$ & hotivation factor). & & & & & \\
\hline
\end{tabular}


input and performance variables all together form the production possibility frontier for the firms concerned. They can be reduced by using multivariate statistics. The various input and output indicators will now concisely be discussed, as they form altogether the ingredients of a conceptual causal model (see Table 2).

Our independent variable personal characteristics comprises 15 items based on the E-Scan of that embrace the following features: the need for achievement, risk-taking propensity and locus of control. The other independent variable business characteristics consists of 11 items which address such elements as: business experience, plant experience, funding, innovation, total number of people working in the enterprise, and business strategy. The two clusters of items representing and forming the personal characteristics and business characteristics variables are further recomputed into one indicator using Principal Component Analysis. A reliability check was undertaken during this process in order to investigate if we could use the constructs for further analysis. This reliability of the clustered indicators and their dimensions were measured with Cronbach's alpha, considering 0.6 or higher to be a critical value (van Velde et al. 2000). The Cronbach's alpha values for all input factors appeared to be sufficient in order to proceed with further research on the impact of the chosen independent variables on the business performance of migrant entrepreneurs.

This data set was used as a statistical input in our DEA model experiments. To take account of socio-cultural differences among migrant entrepreneurs, a distinction is made between the three above-mentioned groups of migrants, while, later on, a further distinction is made according to age, and first- or second-generation migrant education level. The results are presented in Section 5 .

\subsection{Database on migrant entrepreneurs in the service sector in Amsterdam}

Migrant entrepreneurs often have to work in an unfamiliar and risky business environment in urban agglomerations (see Sahin 2012). Some may tend to be risk-avoiding and hence concentrate on traditional market segments (e.g., markets for ethnic products). Consequently, they may be less entrepreneurially-oriented in terms of risk attitudes concerning undertaking innovative business activities. Many migrant entrepreneurs appear to operate in limited markets with products oriented towards their own ethnic or sociocultural group. Clearly, urban social bonds and networks offer a support system for these entrepreneurs. In such a captive market the prospects for break-outs towards serving the wider community are almost nil, as these markets are by definition limited and competitive (the 'ethnic mobility trap'; see Wiley 1970).

Reliance on social networks of their own socio-cultural group in a city may guarantee a certain market share, but may at the same time hamper an outreach strategy towards new and innovative markets (e.g., hiICT)/ICT). A creative 'break-out' action line geared towards innovative activities may strengthen the economic position of migrants and also contribute to urban vitality by bringing new opportunities to the multicultural Dutch cities in the Netherlands. According to Baycan-Levent et al. (2004), a 'break-out' strategy in migrant entrepreneurship can be conceived of as a strategy to escape from the lock-in situation of a relatively small market niche, in which a certain migrant group has a dominant socio-economic position regarding several strategic business factors (e.g., capital, clients, and employees). The latter study argues that migrant entrepreneurship is on a rising curve, especially in the large cities in the Netherlands, but 
most migrant entrepreneurs are still found in traditional, low-growth branches of the Dutch economy. In the major Dutch cities, migrant entrepreneurs have gained a prominent position. It seems, however, plausible that they confirm the hypothesis of Light and Roach (1996) that they earn - despite their involvement in traditional branches more than their fellow migrant workers in paid jobs ('the self-employment bonus').

Despite the rise of entrepreneurs in Dutch cities with a migrant background, it is still an open question whether these entrepreneurs are innovative in the Schumpeterian sense (see also Engelen 2002; O'Sullivan 2000). Are their business competences higher than those of native entrepreneurs in the Netherlands (where competences refer to organizational and management skills, proper strategies for coping with market and technical uncertainties, an innovative attitude associated with 'animal spirits', and network participation; see also Cooke and Morgan 1998; Whitley 2000)? According to Lin et al. (2006), there is no single route to entrepreneurial success or failure; successful entrepreneurs are those who can adjust their entrepreneurial strategies according to their social capabilities. So, which factors determine the performance of migrant business firms? To that end, we present an explanatory migrant business system which maps out the various forces at work in a competitive urban business environment. This framework offers our testable model (see Figure 2). This model is a prototype model of a more comprehensive model designed by Sahin (2012), coined the Galaxy model.

Our study primarily addresses the entrepreneurial behaviour of migrants in the city of Amsterdam - with a focus on their personal characteristics, socio-cultural bonds and managerial skills - from a multicultural urban perspective, in order to perform a quantitative assessment of the critical success factors (CSFs) for migrant entrepreneurs in a cultural network context with the aim of improving business performance in a competitive urban environment. Figure 2 shows the relationship between culture and social networks with a view to the identification of critical success factors (CSFs) for the business performance of migrant entrepreneurs. Those factors are linked to their success and entry into new business markets of migrant entrepreneurs of different ethnic origin in Dutch cities. To that end, it is important to specify relevant input factors that may explain quantitatively the performance (output factors) of these entrepreneurs. Our approach will be applied to an extensive data set on the motives, CSFs, and cultural background of a sample of migrant entrepreneurs in Amsterdam. The methodology for examining such an analytical model in a quantitative sense, based on DEA, is briefly explained in Section 4.

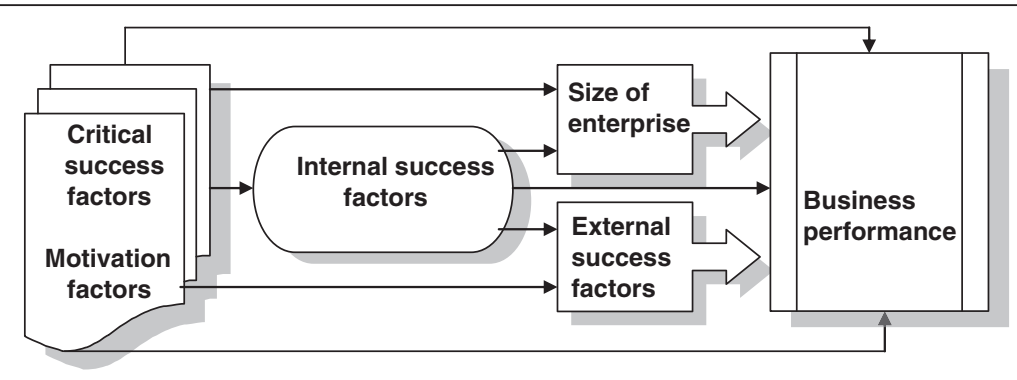

Figure 2 Explanatory framework of the determinants of migrant entrepreneurship. 


\section{Data envelopment analysis as an assessment tool for comparing the business performance of firms}

Data Envelopment Analysis (DEA) is a somewhat new "data-oriented" approach for estimating quantitatively the comparative performance of a set of peer entities called Decision-Making Units (DMUs), which convert multiple inputs into multiple outputs. DEA is essentially a deterministic multi-objective optimization method (thus, dealing with multiple output variables) with the aim to identify actors (DMUs) with the highest productivity (or efficiency). DEA has gained much popularity in performance and benchmark studies (see e.g., Sahin 2012). In recent years, DEA has been extensively applied to operational efficiency problems in public and private sector agencies. This method is particularly useful for comparative studies under conditions of small samples.

In our study, DEA has been applied in order to analyse the efficiency rates of individual entrepreneurs. Details can be found in Sahin, 2010. The general idea is that the production process of a DMU can be described by a generalized production function which may contain multiple input and multiple output factors (see Figure 2). The most efficient production technology of such a composite production process can be described by means of the production possibility frontier, while the actual position of a firm - in terms of its realized efficiency or relative use of input factors to achieve a certain output (or a set of outputs) - can be represented by a point in either the input space or the output space.

A major advantage of DEA is that it does not require any a-priori specified functional form of the production technology, since it is generated from empirical data on observed performance measures (both inputs and outputs). In general, DEA models assess the (in)efficiency of a DMU on the basis of the distance to the production possibility frontier that gives the highest possible efficiency. The efficiency analysis developed by Charnes et al. (1978) aims to maximize production efficiency in terms of the ratio of total weighted output to total weighted input, subject to the condition that, in all circumstances, this efficiency measure is smaller than or equal to 1 , where the value 1 is representing a maximum efficiency. Thus, the distance to the maximum value 1 is then seen as a measure of inefficiency.

A standard approach in DEA is the estimation of weights, which are calculated in a standard way by specifying a multiple-objective maximization model (in case of multiple outputs). In that case, the weights are determined through a maximization exercise carried out for each DMU. The following steps are normally undertaken (for more details, see Cracolici and Nijkamp 2006; Suzuki et al. 2010a). We start with a specification of a fractional maximization problem by each DMU (in terms of ratios of weighted outputs to weighted inputs), with the aim to identify the optimal weights. Then follows a transformation of the above nonlinear maximization problem into a standard linear programming problem in order to compute the input and output weights. This primal linear programming model represents an output-oriented approach, while its dual formulation indicates an input orientation (for a given level of outputs, inputs are minimized). If the solution to the maximization problem leads to a value of 1 for some DMU, then this DMU is efficient (i.e. a case of a non-dominated solution), while a value below 1 indicates a case of inefficiency. Clearly, all points on the efficiency frontier have an equal value of 1 . If one or more inputs or outputs are added to the DEA method, this will affect the selection and the 
number of efficiently-operating DMUs. In general, if more relevant inputs are added, the number of efficient DMUs will rise. Thus, this is a clear reason to pay attention to the specification of the DEA model, while a sensitivity analysis regarding the choice of the inputs or outputs is also desirable.

In Suzuki et al. (2010a, 2010b) a generalized DEA model has been designed, and this is used in our application. This DEA model provides a more effective way to assess the position of non-efficient DMUs, by introducing a generalized Euclidean-based distance friction measure to the production efficiency frontier of DMUs. Thus, this new DEA approach - coined Distance Friction Minimization - is the central tool for explaining differences in the performance of migrant entrepreneurs in Amsterdam, using recently developed software described in Suzuki et al. (2010a, 2010b). The basic idea is that each migrant entrepreneur is a multi-product organization (DMU) that has a set of distinct input descriptors and a set of multiple output (or performance) indicators (see Table 2 for details). The relative efficiency in using inputs to generate outputs is then a measure of the economic success of a DMU, where the relative success performance ranges from 0 (i.e., totally inferior efficiency) to 1 (maximum efficiency). Thus, a DMU with a DEA score of 1 may be regarded as a 'high performer' (i.e., with the highest productivity in a multi-input multi-output sense), who may be seen as a benchmark for others. The individual results can then be summarized in an integrated survey table or diagram (see Figure 3). The DEA technique appears to be particularly appropriate for our purposes.

\section{A performance analysis of migrant entrepreneurs in Amsterdam}

\subsection{Efficiency analysis results}

The results of our empirical application of the DEA efficiency analysis will now be presented and interpreted. The DEA approach was applied to each of the three categories comprising the sample of 83 migrant entrepreneurs, thus the DEA model was used separately for each of the three migrant categories in our study (Turks, Moroccans, Surinamese). As mentioned above, this seems statistically to be a relatively small sample, but in case study research and comparative business experiments such numbers are quite common. The main goal is to pinpoint discriminating factors that make a difference for the business performance of the three distinct classes of DMUs. It is not meant to give a statistically representative cross-section of the data. In this context, it is also noteworthy that DEA is not a stochastic analysis, but provides only a deterministic identification of significant differences in the drivers of efficiency and productivity. The results are presented in Figure 3 and lead to the following comments. The vertical bars in Figure 3 illustrates the efficiency rate of DMUs per each distinct migrant group category, in other words, this is an intra-group ranking of the performance of entrepreneurs. Thus, it can be seen that 7 DMUs of Turkish origin, 12 DMUs of Moroccan origin, and 5 DMUs of Surinamese origin are efficient, i.e. have a maximum productivity or performance in their own group. This information shows also that Moroccans perform much better in their own circle as opposed to the broader benchmark group. But the dispersion (in terms of $\mathrm{max} / \mathrm{min}$ ratios) of performance in this group is also larger than in the two other groups. These results prompt the question of why there are such striking differences among the distinct groups of migrant entrepreneurs. We now try to identify the driving forces for the efficiency differences 


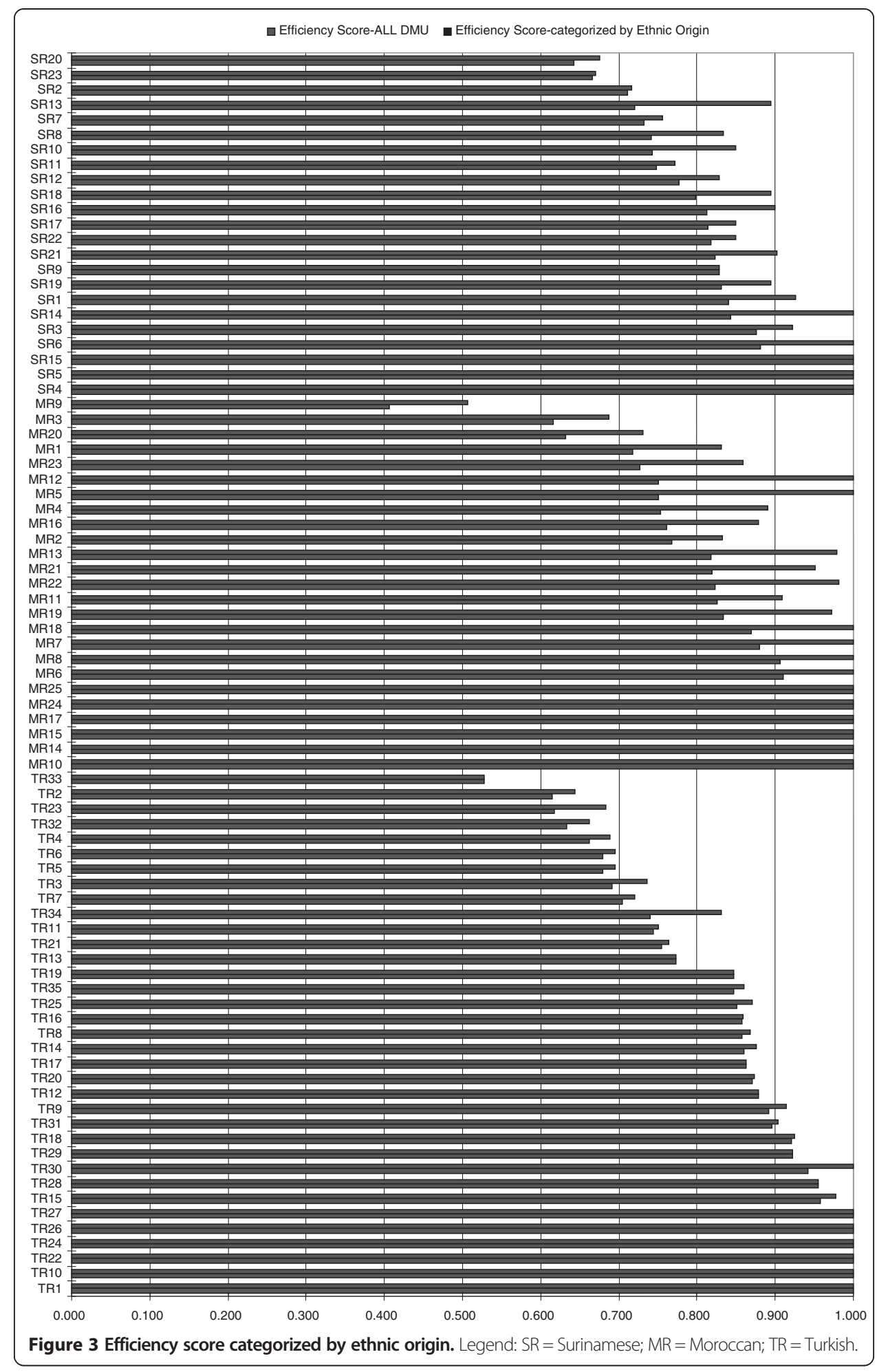

between and within the various ethnic entrepreneurs' groups on the basis of a crossanalysis of our data.

Finally, it should be noted that in a DEA model only those DMUs are taken into consideration that belong to the relevant sample. There is no out-of-sample information 
on other DMUs. Consequently, the DMUs identified as 'high performers' are only the firms which have a maximum efficiency in the relevant set of migrant entrepreneurs.

\subsection{Cross-analysis results}

The next step of the statistical analysis was to perform a cross-analysis in order to investigate the personal characteristics of the entrepreneurs so as to investigate the efficiency of the DMUs regarding several distinct categories. The personal characteristics of the entrepreneurs refer to their ethnic origin, age, gender, generation and education. We determined the efficiency score for each DMU according to the categorization of A (1.00); B (0.99-0.80); and C (0.79-0.00). Value A refers to a maximum efficiency score, and value $\mathrm{C}$ to a minimum efficiency score. We refer to Figures 4, 5, 6 and 7 for the results on country of origin, age and age cohorts.

We first look at the country of origin (see Figure 4). From the 83 entrepreneurs, 35 were of Turkish origin, 25 of Moroccan origin, and 23 of Surinamese origin. If we look at the efficiency score value A equal to 1 , then we see that this top score is achieved by 17.1 per cent of the Turkish entrepreneurs (DMUs), 24.0 per cent of the Moroccan DMUs and 13.0 per cent of the Surinamese DMUs. Concerning value B, which refers to a score between 0.99-0.80, we see that this medium efficiency score is attained by 45.7 per cent of the Turkish DMUs, 36.0 per cent of the Moroccan DMUs, and 43.5 per cent of the Surinamese DMUs. Finally, with respect to value C, which refers to an efficiency score between 0.79-0.00, we see that this lowest efficiency score is assigned to 37.1 per cent of the Turkish DMUs, 40.0 per cent of the Moroccan DMUs, and 43.5 per cent of the Surinamese DMUs. It is interesting to see that most DMUs with a high efficiency score equal to value 1 (A) are of Moroccan ethnic origin. This means that six entrepreneurs of Moroccan ethnic origin perform highly efficiently. Although the Turkish DMUs are the biggest group, they have a lower efficiency score. 37.1 per cent of the Turkish DMUs have an efficiency score of value C, and only 17.1 per cent of this group perform efficiently. These results are shown in Figure 5.

Next, we address the age impacts. From Figure 5, we can see that most entrepreneurs interviewed were in the age range 26 to 30 (29 per cent). However, this was different for each migrant group. Most entrepreneurs of Turkish origin were in the age group 30-35 (10.8 per cent), while most of the entrepreneurs of Moroccan origin were in the

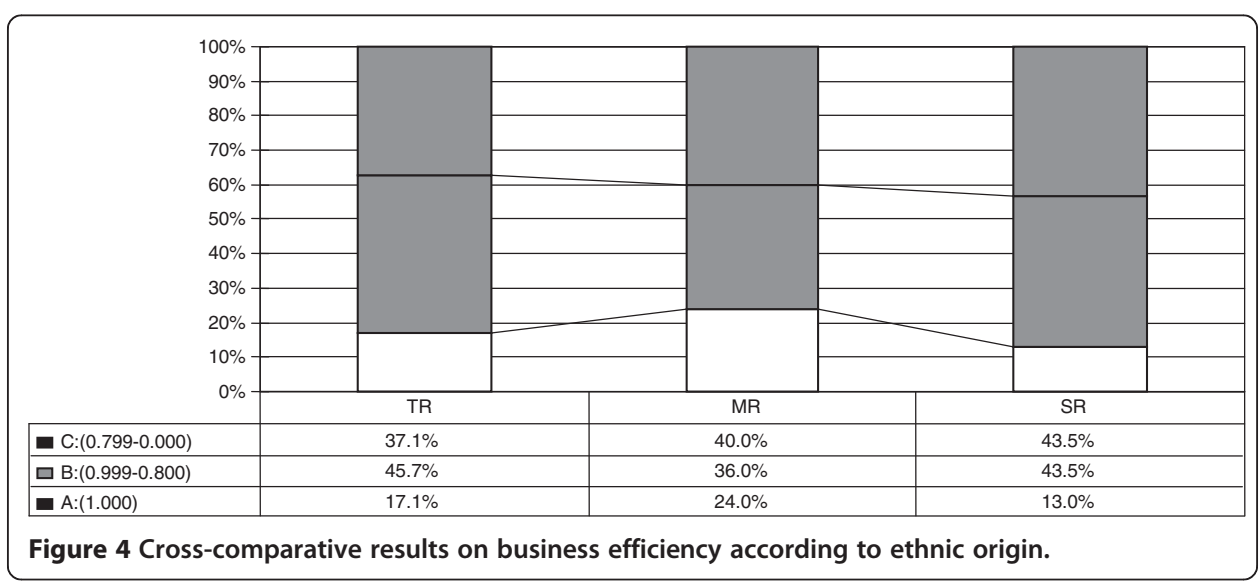




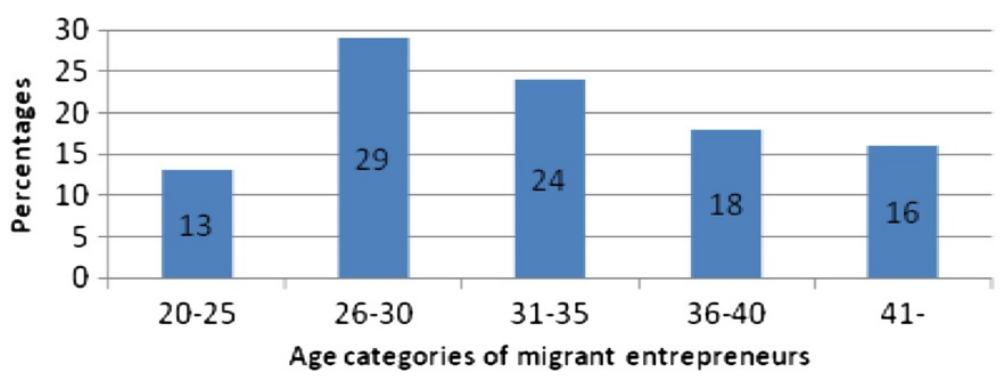

Figure 5 Distribution of age of migrant entrepreneurs.

age group 25-30 (15.7 per cent), and most of the Surinamese entrepreneurs were in the age group 35-39 (8.4 per cent).

As a third step, we investigated the age cohorts of migrant entrepreneurs (see Figure 6). When we consider the age category of the DMU sample, it is interesting to see that most entrepreneurs are in the age range 26 to 30, which is a relatively young group. It is also interesting to see that 25 per cent of this age category have a high efficiency score equal to value A (i.e., 1.0). But, on the other hand, 54.2 per cent of the same group have the lowest efficiency score of value $C$ (i.e., 0.79-0.00). Thus, this group has both the most efficient and the most inefficient entrepreneurs (DMUs). The most entrepreneurs with an efficiency score of value B, which is equal to 0.99-0.80, are in the age category 41 and older. This means that 69.2 per cent of the DMUs aged 41 and older are performing at a moderate level.

In our study we are particularly interested in the development of new activities by second-generation migrants in order to trace innovation attitudes. Therefore, we made a distinction in terms of first- and second-generation migrants (see Figure 7). Many migrants in the Netherlands originate from non-Western countries (e.g., Turkey, Morocco, Surinam and the Dutch Antilles). These migrants belong to either the first generation or the second generation. The first-generation category refers to entrepreneurs who were born in a foreign country (another country than the Netherlands). The second-generation category refers to entrepreneurs who were born in the Netherlands with at least one parent born in a foreign country. In our sample, we only included migrants from Turkey, Morocco, and Suriname, because of their involvement in the service sector, and, moreover, the entrepreneurship rate for the main migrant groups

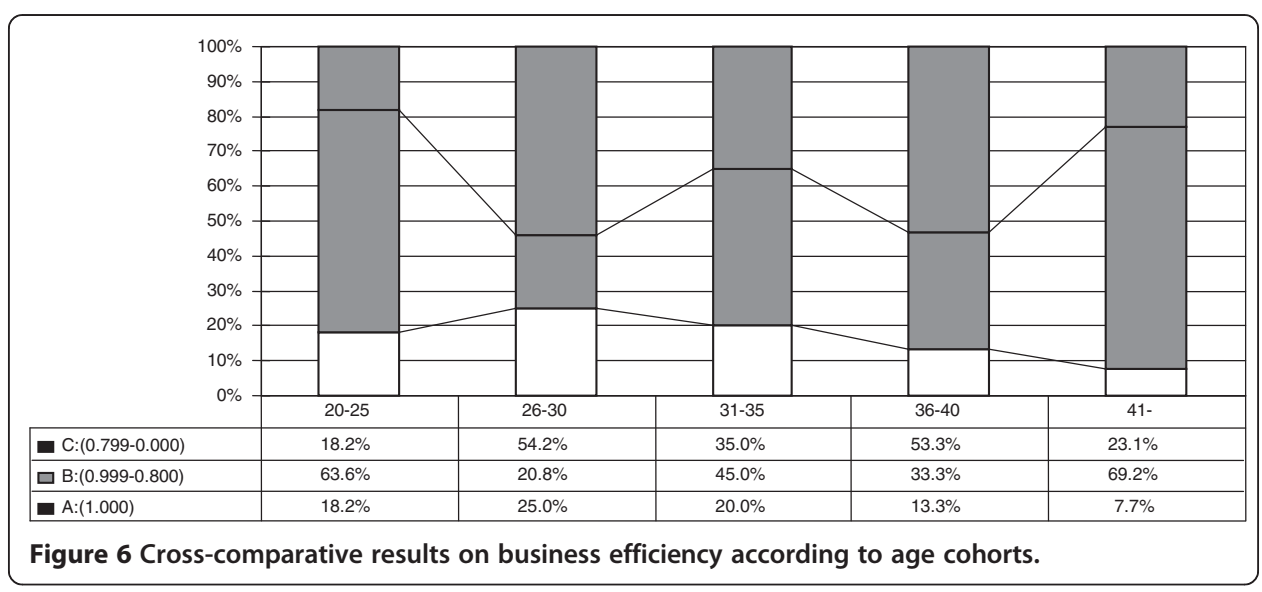




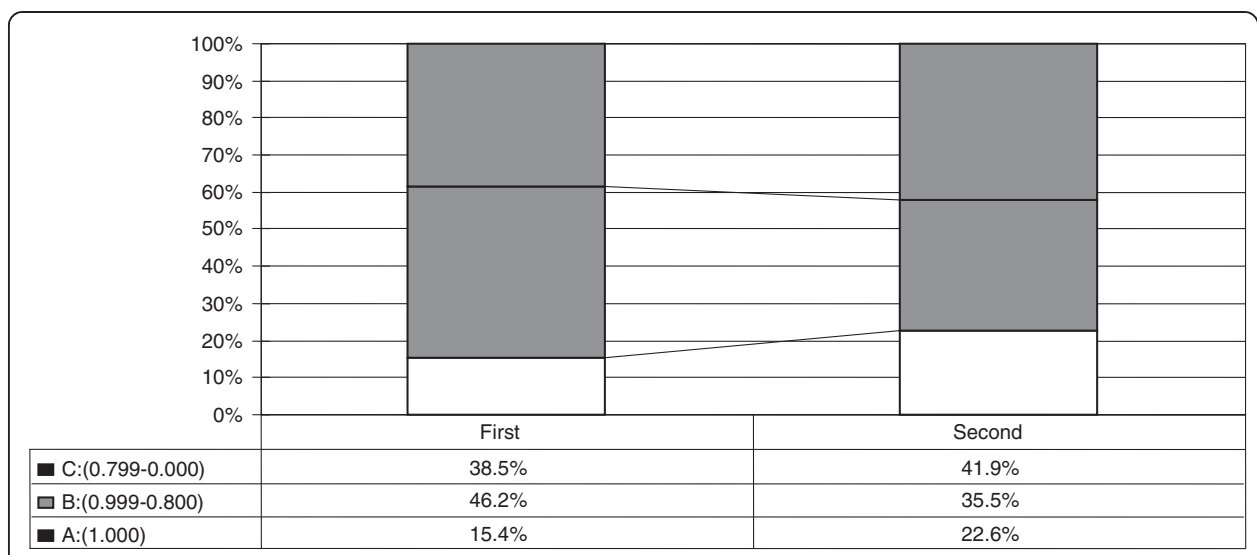

Figure 7 Cross-comparative results on business efficiency according to generation.

Turks, Moroccans, and Surinamese is increasing in the Netherlands. As yet, hardly any increase has been observed in the number of Antillean entrepreneurs.

It is interesting to see that 22.6 per cent of the second-generation DMUs have a high efficiency score equal to value A (1.00) (see Figure 7), while only 15.4 per cent of the first-generation DMUs have an efficiency score of value A. It is also very interesting to see that the second-generation DMUs have the highest efficiency score of value $C$, which is equal to $0.79-0.00$.

Next, we address the impact of education from Figure 8, we can derive that 37 per cent of the respondents from the total sample have a high vocational education level (HBO). If we look at the University level, we can derive that 31 per cent of the approached migrant entrepreneurs have a University degree. This means that most respondents went to a school with a high education level. When comparing the level of education for the three groups, in particular, we can conclude that in all groups most of the respondents have a level of education representing a high vocational education (HBO). For example, among the Turkish entrepreneurs 13.3 per cent of the respondents have a high vocational education level compared with 14.5 per cent of Moroccan entrepreneurs and 8.4 per cent of the Surinamese entrepreneurs. However, if we only look at the University level, we can conclude that most of the respondents of Surinamese origin went to University and have the highest level of education, viz. university level (WO).

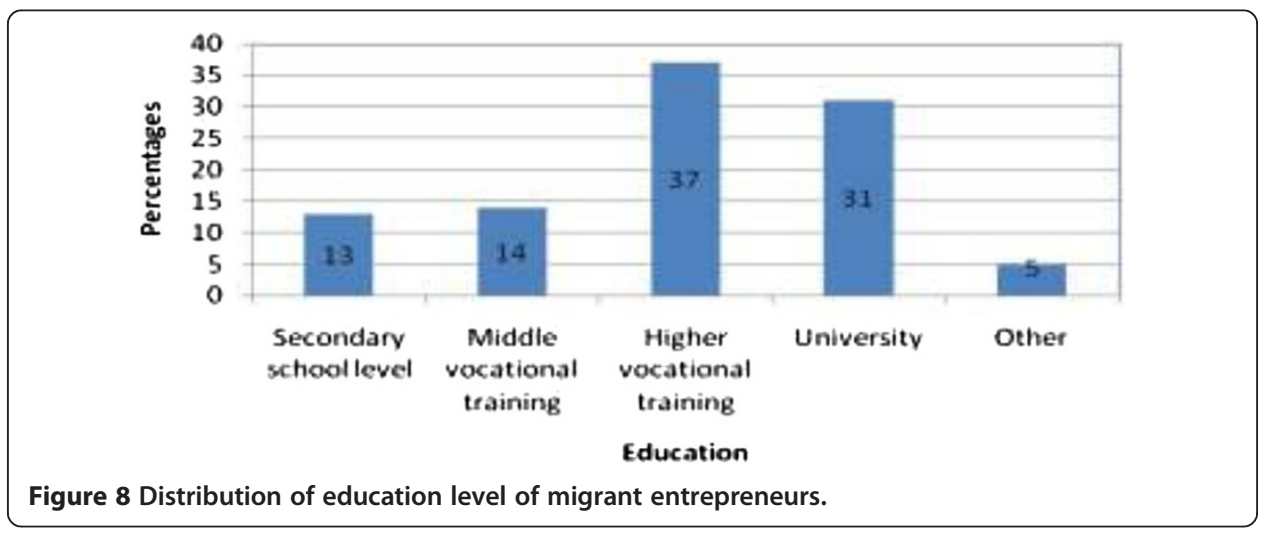


And, finally, we looked in a more detailed way into education impacts at medium and higher levels as a discriminatory variable (see Figure 9). Regarding the education level, we made a distinction between vocational (MBO), high vocational (HBO) and university (WO) education. 30 of the DMUs have a high vocational education level (HBO). It is very interesting to see that 30.8 per cent of the DMUs with a university education have an efficiency score of value A. The most efficient DMUs have a university education. 30.8 per cent of the DMUs with a university education have an efficiency score of value A, while no DMUs with secondary education and other education levels have an efficiency score of value A. This means that their businesses are not performing efficiently. The other efficiently-performing group refers to DMUs with a high vocational education. 20.0 per cent of this group have an efficiency score of value A (1.00). We can conclude, therefore, that a higher level of education tends to improve the efficiency score of the DMUs.

In conclusion, we can confirm our hypothesis that migrant entrepreneurs comprise heterogeneous firms, with significant differences in performance and performance conditions. The critical factors determining these differences are in particular: country of origin, age and age cohort, education, and first- and second-generation migrant group.

\section{Policy perspectives}

The phenomenon of ethnic entrepreneurship calls for new policy perspectives in a dynamic urban environment. According to Sahin (2012), the main advantage of ethnic entrepreneurship is its contribution to reducing social exclusion and to raising living standards in groups that can often be among the most disadvantaged in society. Migrant entrepreneurs contribute to the supply of a more diversified range of products, increasing competition, and, indirectly, the quality of products. Furthermore, the benefits of ethnic entrepreneurship accrue from social bonds in a cultural network, which create flexible ways to attract personnel and capital and the capacity of generate market niches for specific cultural goods (e.g., music and food). In countries like the Netherlands and the US, migrant entrepreneurship has proven to be an efficient means of socio-economic participation contributing significantly to the overall economic growth and development of the area concerned. Ethnic entrepreneurship has a social as

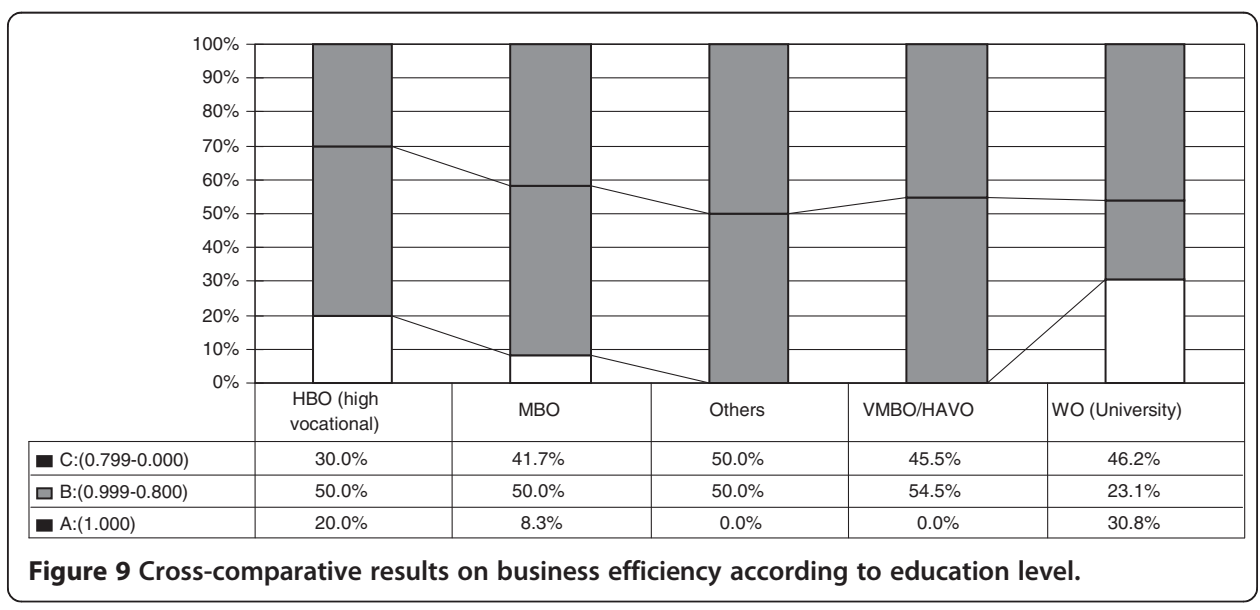


well as an economic impact on a society's development in both the short-term and long-term perspective. Exploiting ethnic entrepreneurs as growth engines is thus highly important, for both social and economic reasons.

Migrant entrepreneurship is an area that calls for thorough scientific investigation. Of utmost importance is to identify the CSFs of migrant enterprises, which can range from factors at the micro-level to those at a macro-level. Our research addresses a specific niche in the wealth of ethnic entrepreneurship research, viz. the analysis of disparities in the economic performance (efficiency) of different groups of migrant entrepreneurs, through the use of a generalized DEA model. The results of our DEA analysis demonstrate that, on the basis of their efficiency rate, the performance of migrant entrepreneurs may significantly vary based on their efficiency rate. We have analysed both the efficiency of all migrant firms clustered together and also the efficiency of separate migrant groups.

Our results based on micro-oriented field research demonstrate clearly a significant heterogeneity among migrant entrepreneurs, not only between different ethnic groups but also within ethnic groups. Our causal framework - supported by DEA experiments - has brought to light the existence of five major critical background conditions that explain this heterogeneity: country of origin, age, age cohort, first- or second-generation, and education. Another interesting finding is that in terms of business performance the second generation of migrant firms is more successful, mainly as a result of innovative break-out strategies of these firms.

Clearly, our findings are provisional and call for further research, as it would be interesting to compare the reasons for the success of those DMUs that had the highest efficiency scores - equal to 1 - in a DEA analysis. Another interesting research area to examine would be the possibilities (barriers and opportunities) for migrant entrepreneurs to go beyond their ethnic frontiers and to expand their activities into broader and other market segments and business lines, competing or liaising with native Dutch entrepreneurs on their own markets. In this framework, the focus might be on the improvement of their skills and knowledge of the Dutch language.

Our research has identified different target groups, distinguished according to ethnicity, education, age or gender. In countries oriented towards target-group policies, the primary reason of dealing with labour market problems is to cope with - higher levels of unemployment or inadequate labour market integration. Sometimes, such targetgroup policies are more directed at creating future urban economic growth. Business ownership offers an option for self-sufficiency, socio-economic empowerment, and new jobs. The range of services offered by several governments includes counselling and mentoring, the provision of micro-credits and seed capital funds, award programmes, business networks, promotion of entrepreneurship as a promising option for young people, and tailored information (e.g., in the language of the minority group). It may be interesting to explore effective policy strategies in future research. Interesting and promising initiatives for stimulating new entrepreneurship can be found, for example, in the US. The US offers a wealth of 'full-service' initiatives for less privileged entrepreneurial groups. (For instance, enterprise centres for women, native Indians, and ethnic minority segments). These are complemented with special support systems, such as micro-loan funds, entrepreneurship award programmes, networking and mentoring programmes, innovation incentives, and so forth. Indeed, a broadly developed business 
culture forms the seedbed for migrant entrepreneurship, especially in the SME sector. Europe has a wide variety of business support initiatives, but does not yet have a uniform incentive program for migrant entrepreneurship, despite its significance in large urban agglomerations. Migrant entrepreneurship will certainly be a major source of urban dynamics in the year to come, also in Europe.

\section{Competing interest}

The IZA Journal of Migration is committed to the IZA Guiding Principles of Research Integrity. The authors declare that they have observed these principles.

\section{Acknowledgement}

Very helpful comments by an anonymous referee are appreciated. (Financial support of the NORFACE Migration Programme as well as very helpful comments by an anonymous referee are gratefully acknowledged). This paper was presented at the IZA and Centre on Human Capital Workshop on 'Migration and Human Capital' (Bonn, May 23-24, 2013). This workshop was organized in collaboration with the Journal of Human Capital and the IZA Journal of Migration. Responsible Editor: Corrado Giulietti.

\section{Author details}

${ }^{1}$ Department of Spatial Economics, VU University, De Boelelaan 1105, 1081 HV Amsterdam, The Netherlands. ${ }^{2}$ A. Mickiewicz University, Poznan, Poland. ${ }^{3}$ Department of Civil and Environmental Engineering, Hokkai-Gakuen University, 1-1, South26 West 11, Chuo-ku Sapporo 064-0926, Japan.

Received: 2 July 2013 Accepted: 20 January 2014

Published: 22 Apr 2014

\section{References}

Acs ZJ, De Groot HLF, Nijkamp P (eds) (2002) The Emergence of the Knowledge Economy. Springer Verlag, Berlin Audretsch DB, Grilo I, Thurik AR (eds) (2007) Handbook of Entrepreneurship Policy. Edward Elgar, Cheltenham Bates T (1997) Race, Self-Employment and Upward Mobility. Woodrow Wilson Center, Washington DC

Baycan-Levent T, Masurel E, Nijkamp P (2003) Diversity in entrepreneurship: ethnic and female roles in urban economic life. Int J Soc Econ 30(11):1131-1161

Baycan-Levent T, Masurel E, Nijkamp P (2004) Trends in Break-out Strategies of Ethnic Entrepreneurs. In: Vaz T, Morgan E, Nijkamp P (eds) The New European Rurality: Strategies for Small Firms. Ashgate, Aldershot, pp 143-156

Baycan-Levent T, Nijkamp P, Sahin M (2009) New orientations in ethnic entrepreneurship: motivation, goals and strategies of new generation ethnic entrepreneurs. Int J Foresight Innov Policy 5:83-111

Borjas GJ (1991) The economic impact of immigration. Am Econ Rev 81(2):287-291

Carter S, Jones-Evans D (eds) (2006) Enterprise and Small Business; Principles, Practice and Policy. Prentice Hall, London

CBS (Central Bureau of Statistics) (2007) Allochtonen in Nederland 2003. , Voorburg

Chaganti R, Greene PG (2000) Who are migrant entrepreneurs? A study of entrepreneurs migrant involvement and business characteristics. J Small Bus Manag 40:126-143

Charnes A, Cooper WW, Rhodes E (1978) Measuring the efficiency of decision making units. Eur J Oper Res 2:429-444

Choenni A (1997) Veelsoortig Assortiment. Het Spinhuis, Amsterdam

Clark K, Drinkwater S (1998) Ethnicity and Self-Employment in Britain. Oxf Bull Econ Stat 60:383-407

Cooke T, Morgan K (1998) The Associational Economy. Oxford University Press, Oxford

Cormack J, Niessen J (2002) Supplier Diversity, The Case of Immigrant and Ethnic Minority Enterprises. Background paper prepared for the Transatlantic Round Table on Supplier Diversity, Brussels

Cracolici MF, Nijkamp P (2006) Competition among Tourist Destinations, Tourism and Regional Development. In: Giaoutzi M, Nijkamp P (eds). Ashgate, Aldershot, pp 133-152

Cummings S (ed) (1980) Self-Help in Urban America. Kenikart Press, New York

Dana LP (ed) (2006) Migrant Entrepreneurship. Edward Elgar, Aldershot

De Graaff T, De Groot HLF (2004) Ethnic Concentration and Human Capital Formation. In: Capello R, Nijkamp P (eds) Urban Dynamics and Growth: Advances in Urban Economics. Elsevier, Amsterdam

Deakins D, Majmudar M, Paddison A (1997) Developing success strategies for ethnic minorities in business: evidence from Scotland. New Community 23(3):325-342

EIM (2004) Monitor Etnisch Ondernemerschap 2004. Ministerie van Economische Zaken, Zoetermeer

Engelen E (2002) How innovative are Dutch immigrant entrepreneurs. Int J Entrepreneurial Behav Res 8(1):69-92

Geenhuizen MS, Van, Nijkamp P (eds) (2012) Creative Knowledge Cities. Edward Elgar, Cheltenham

Glaeser EL (2011) The Triumph of the City. Macmillan, London

Glaeser EL, Laibson DK, Scheinkman JA, Soutter CL (2000) Measuring trust. Q J Econ 115(3):811-846

Greenwood MJ (1994) Potential channels of immigrants' influence on the economy of the receiving country. Pap Reg Sci 73:211-240

Jenkins SP (1984) Winners and Losers: A Portrait of the UK Income Distribution of Swansea Department of Economics, Discussion Paper, No. 94-97

Kloosterman R, Rath J (2001) Immigrant entrepreneurs in advanced economies: mixed embeddedness further explored. J Ethn Migr Stud 27(2):189-201

Kloosterman R, Van Der Leun J, Rath J (1999) Mixed embeddedness: (in)formal economic activities and immigrant businesses in the Netherlands. Int J Urban Regional Res 23(2):252-266

Light I, Roach E (1996) Self-employment: Mobility Ladder or Economic Lifeboat. In: Waldinger R, Bozorgmehr M (eds) Ethnic Los Angeles. Russell Sage, New York, pp 193-213 
Lin B, Li P, Chen J (2006) Social capital, and entrepreneurial strategies: a study of Taiwanese high-tech new ventures. Technol Forecast Soc Chang 73(2):168-181

Longhi S, Nijkamp P, Poot J (2007) The fallacy of 'Job Robbing': a meta-analysis of estimates of the effect of immigration on employment. J Immigration Refugee Stud 1(4):131-152

Metcalf H, Modood T, Virdee S (1996) Asian self-employment; the interaction of culture and economics in England. Policy Studies Institute, London

Mitter S (1986) Industrial restructuring and manufacturing homework. Capital and Class 27:37-80

Nijkamp P (2003) Entrepreneurship in a modern network economy. Reg Stud 37(4):395-405

Nijkamp P, Sahin S (2009) Performance Indicators of Urban Migrant Entrepreneurship in the Netherlands. Research Memorandum 2009-34. Faculty of Economics, VU University, Amsterdam

Nijkamp P, Sahin M, Baycan T (2010) Migrant entrepreneurship and new urban economic opportunities - identification of critical success factors by means of qualitative pattern recognition analysis. Tijdschrift voor Economische en Sociale Geografie (Journal of Economic and Social Geography) 101(4):371-391

Nijkamp P, Poot J, Sahin S (eds) (2012) Migration Impact Analysis: New Horizons. Edward Elgar, Cheltenham

O'Sullivan M (2000) The innovative enterprise and corporate governance. Camb J Econ 24:393-416

Oliveira CR, Rath J, Eds (2008) Immigrant Entrepreneurship, Special issue. Migrações Journal 3(Oct):1-287

Ram M, Jones T (1998) Ethnic Minorities in Business. Open University Press, Milton Keynes

Ram M, Smallbone D (2002) Ethnic minority business support in the era of the small business service. Environ Planning C: Gov Policy 20:235-249

Razin E, Light I (1988) Ethnic entrepreneurship in America's largest metropolitan areas. Urban Aff Rev 33:332-360

Rusinovic K (2006) Dynamic Entrepreneurship: First and Second-Generation Immigrant Entrepreneurs in Dutch Cities, Dissertation. University of Amsterdam, Amsterdam

Rusinovic K (2008) Moving between markets? Immigrant entrepreneurs in different markets. Int J Entrepreneurial Behav Res 14(6):440-454

Sahin M (2012) Studies on Migrant Entrepreneurship in Dutch Cities. VU University, PhD Dissertation, Amsterdam

Sahin M, Nijkamp P, Rietdijk M (2009) Cultural diversity and urban innovativeness: personal and business characteristics of urban migrant entrepreneurs. Innovation Eur J Soc Sci Res 22(3):251-281

Santarelli E (ed) (2006) Entrepreneurship, Growth, and Innovation. Springer, Berlin

Sassen S (1991) The Global City. Princeton University Press, Princeton, NJ

Suzuki S, Nijkamp P, Rietveld P, And PE (2010a) A distance friction minimization approach in data envelopment analysis; an application to airport performance. Eur J Oper Res 207(2):1104-1115

Suzuki S, Nijkamp P, Rietveld P (2010b) Regional efficiency improvement by means of data envelopment analysis through Euclidean distance minimization including fixed input factors: an application to tourist regions in Italy. Pap Reg Sci 90(1):67-89

Tillie J, Slijper B (2006) Immigrant political integration and ethnic civic communities in Amsterdam. In: Benhabib S, Shapiro I (eds) Identities. Allegiances and Affiliations, Cambridge University Press, Cambridge

Van Velde MEG, Jansen PGW, Telting IA (2000) Bedriffswetenschappelijk Onderzoek: Van Probleemstelling tot Presentatie. Nelissen, Baarn

Waldinger R (1988) The ethnic division of labour transformed: native minorities and new immigrants in post-industrial New York. New Community 14(3):23-38

Waldinger R (1996) Still the Promised City? Harvard University Press, Cambridge MA

Waldinger R, Aldrich H, Ward R (eds) (1990) Ethnic Entrepreneurs. Sage Publishers. Newbury Park, Ca

Whitley R (2000) The Institutional Structuring of Innovation Strategies. Organ Stud 21(5):855-886

Wiley NF (1970) The Ethnic Mobility Trap and Satisfaction Theory. In: Rose PI (ed) The Study of Society. Random House, New York, pp 397-408

Yin R (1984) Case Study Research, Design and Methods, 1st edn. Sage, Beverly Hills, CA

10.1186/2193-9039-3-7

Cite this article as: Sahin et al:: Contrasts and similarities in economic performance of migrant entrepreneurs. IZA Journal of Migration 2014, 3:7

\section{Submit your manuscript to a SpringerOpen ${ }^{\circ}$ journal and benefit from:}

- Convenient online submission

- Rigorous peer review

- Immediate publication on acceptance

- Open access: articles freely available online

- High visibility within the field

Retaining the copyright to your article

Submit your next manuscript at $\boldsymbol{s p r i n g e r o p e n . c o m ~}$ 